\title{
Ferramenta de apoio ao ensino presencial utilizando gamificação e design de jogos.
}

\author{
Adair P. Falcão ${ }^{1}$, Maici D. Leite ${ }^{1}$, Marcos M. Tenório ${ }^{1}$ \\ ${ }^{1}$ Licenciatura em Informática - Universidade Tecnológica Federal do Paraná (UTFPR) \\ Campus Francisco Beltrão Caixa Postal 135 - 85.601-970 - Francisco Beltrão - PR - Brazil \\ adairfalcao@hotmail.com.br, maicileitedutfpr.edu.br, \\ marcostenorio@utfpr.edu.br
}

\begin{abstract}
This study presents a tool to support learning, that uses gamification and game design to stimulate the interest of students outside of the classroom, working as a mediator for the digital environment and the contents seen in class, leading to students an more friendly environment, reinforcing learning and generating new goals for contents addressed, aimed a change in student behavior, to promote knowledge outside the classroom, all to achieve the pedagogical goals in an educational institution.

Resumo. O presente estudo apresenta uma ferramenta de apoio à aprendizagem, que faz uso gamificação e design de jogos para estimular o interesse dos alunos fora da sala de aula, atuando como um mediador aproximando o meio digital aos conteúdos vistos em sala, levando aos alunos um ambiente mais amigável, reforçando o aprendizado e gerando novos objetivos para os conteúdos abordados, visando causar uma mudança de comportamento nos alunos, para que busquem conhecimento extraclasse, tudo isso para se alcançar os objetivos pedagógicos em uma instituição de ensino.
\end{abstract}

\section{Introdução}

A informática e o meio digital vêm ganhando mais espaço no cotidiano e cultura da sociedade. As novas gerações já nascem e crescem em um mundo digital e informatizado; convivendo com novas tecnologias, vivenciando experiências e aprendizado através do computador, internet, vídeo game e celular (Prensky, 2000).

Essas novas gerações, chamadas de nativos digitais, já crescem familiarizados com essas tecnologias e com os métodos de ensino digitais (Prensky, 2000), entretanto, as aulas tradicionais não oferecem suporte a estes recursos, desmotivando o aluno. Esta falta de motivação do aluno surge da ausência de envolvimento emocional e de atitudes lúdicas normalmente deixadas de lado após o ensino primário (Lee e Doh, 2012).

A falta de envolvimento e motivação do aluno afeta diretamente o aprendizado e compreensão do conteúdo estudado. Quando o aluno aprende ganha confiança e motivação para continuar aprendendo, portanto, a motivação e o envolvimento do aluno estão diretamente associados ao aprendizado, onde aprender motiva a aprender (Moraes e Varela, 2007).

A prática de ensino que a maioria dos professores vem utilizando está centrada na utilização de métodos pedagógicos tradicionais que consideram o aluno apenas como um receptor de conteúdos, com pouca ou quase nenhuma interação, obrigando-o a 
memorizar cada vez mais conteúdos, fazendo que o aluno perca o interesse e o envolvimento com a disciplina; dificultando o aprendizado (Tapia e Fita, 2006).

Para as novas gerações surge a necessidade de um novo mediador para atuar como motivador para o aluno, que promova o ensino lúdico e ao mesmo tempo aproxime o meio digital (presente no cotidiano do aluno) ao aprendizado em sala de aula, levando ao aluno um ambiente de aprendizado mais amigável, reforçando os conteúdos da aula e gerando novos objetivos para os conteúdos abordados (França e Reategui, 2013).

Existem diversas plataformas criadas para o apoio ao ensino, um exemplo é o Moodle, que além de um gerenciador de curso é um ambiente virtual de aprendizagem. Este é um aplicativo web que os educadores utilizam na criação de sites de aprendizado. Muitas instituições utilizam o Moodle somente como um meio de fornecer conteúdo aos alunos e avaliar a aprendizagem utilizando tarefas ou testes (Moodle, 2014).

Entre as inúmeras funcionalidades e usos para uma ferramenta de apoio uma das mais importantes é a construção da aprendizagem fora da sala de aula, porém, quando o professor utiliza tal ferramenta somente para fornecer conteúdos e avaliar a aprendizagem, a utilização efetiva pelos alunos diminui, assim como o seu interesse, passando a acessar o sistema apenas para realizar pequenas atividades ou para efetuar o download do material para o estudo, logo, o tempo de permanência no site decresce.

Gamificação é um sucesso recente em web sites que desejam criar lealdade, compromisso e participação, como os sites Foursquare e Stack Overflow (Daniels, 2010), podendo assim alcançar importância no ambiente educacional ao incorporar elementos de jogos em atividades onde se deseja aumentar a motivação (Shneiderman, 2004), mas, para isso é preciso prestar atenção à integração de tarefas e exercícios dentro do design de jogos, especialmente para incentivar a participação de alunos em ambientes fora da sala de aula (Von Ahn e Dabbish, 2008).

A gamificação consiste no uso de elementos de jogos em contextos não jogos (Deterdings et al., 2011) e foca-se na motivação extrínseca; já design de jogos centra-se na motivação intrínseca e nos elementos que geram maior engajamento emocional, visando com que o contexto se torne um jogo e o usuário se sinta em um jogo (Haksu e Doh, 2012). Não se pode confundir gamificação com criar um jogo; não se encaixa também na categoria de jogos educacionais, mas sim trata de incentivar $o$ comportamento correto que está alinhado com objetivos pedagógicos.

No contexto de jogos na motivação intrínseca o usuário decide quando agir ou não, alguns exemplos são altruísmo, competição, cooperação, companheirismo, amor ou agressão. Já motivações extrínsecas são classificações, níveis, pontos, medalhas, recompensas, missões (Viola, 2011).

O estudo propõe uma plataforma de apoio ao estudante que utiliza os conceitos de gamificação e de elementos de design de jogo, visando a criação de um ambiente que estimule o interesse e a atenção do aluno fora da sala de aula e ao mesmo tempo o incentive a continuar aprendendo, entretanto, não é o nosso objetivo que o aluno apenas se sinta em um jogo, ou entre em uma disputa por notoriedade e status, mas sim, causar uma mudança de comportamento dos alunos motivando-os a estudar e buscar conhecimento fora da sala de aula. 


\section{Regras e mecanismos}

É necessário criar regras específicas para aplicação de gamificação em um sistema voltado à aprendizagem. Todas as regras para o desenvolvimento correto precisam ser estabelecidas para que os objetivos sejam alcançados (Bista et al, 2012). O processo de criação do sistema é composto pelas seguintes fases conforme apresentado na Tabela 1.

Tabela 1 - Fases para elaboração da gamificação adaptado de (Bista et al, 2012)

$\begin{array}{ll}\underline{\text { Fases }} & \underline{\text { Atividades }} \\ \underline{\underline{\text { Contexto }}} & \underline{\text { Identificar contextos de gamificação }} \\ \underline{\underline{\text { Acões dos alunos }}} & \underline{\text { Identificar possíveis ações dos alunos }} \\ \underline{\underline{\text { Pontos }}} & \underline{\text { Identificar a abrangência dos pontos }} \\ \underline{\text { Regra dos pontos }} & \underline{\text { Alocar pontos a ações }} \\ \underline{\text { Conquistas e emblemas }} & \underline{\text { Identificar o conjunto de conquistas }} \\ \underline{\underline{\text { Regra dos emblemas e e }}} & \underline{\text { Relacionar conquistas a pontos e outras }} \\ \underline{\text { atividades }}\end{array}$

$\mathrm{Na}$ primeira fase é necessário identificar o conjunto de contextos onde a gamificação deverá ser aplicada, ou seja, as regras de onde os alunos podem participar. Alguns contextos são idealizados pelas possíveis ações dos alunos (segunda fase), a Tabela 2 elenca alguns dos contextos estabelecidos que podem ser "gamificados" com as ações dos alunos. Está etapa pode ser considerada uma das mais importantes, pois é aqui que se define o contexto "jogável".

Tabela 2 - Alguns contextos de gamificação e ações atribuídas aos mesmos

\begin{tabular}{ll} 
Contexto de gamificação & $\underline{\text { Ação }}$ \\
\hline$\underline{\text { Registro }}$ & $\underline{\text { Completar o cadastro; convidar }}$ \\
$\underline{\text { Fórum }}$ & $\underline{\text { Criar; Comentar; Avaliar }}$ \\
$\underline{\text { Material extra }}$ & $\underline{\text { Ler; Enviar; Avaliar }}$ \\
$\underline{\text { Atividades }}$ & $\underline{\text { Completar atividades }}$ \\
$\underline{\text { Desafio }}$ & $\underline{\text { Completar os desafios }}$
\end{tabular}

O contexto do Registro é simples, podendo o aluno completar e alterar o cadastro e convidar outros alunos a se cadastrarem no sistema. No contexto do fórum os alunos poderão criar novos tópicos, como ocorre em um fórum normal, podem também comentar e discutir sobre diversos assuntos relacionados ou não com a disciplina, o aluno também poderá avaliar tópicos e comentários realizados.

O professor dentro do contexto "desafio" propõe uma hipótese e estipula um tempo para que os alunos tomem partido contra ou a favor, levantando argumentos para defender ou derrubar a hipótese, os argumentos são avaliados pela comunidade em geral e ao final do período os alunos que apresentaram argumentos coerentes recebem uma 
recompensa. O professor também pode propor desafios na forma de atividades mais complexas ou que envolvam outros critérios como tempo, propondo a resolução de um exercício rapidamente.

No contexto "material," os alunos poderão enviar materiais de autoria própria ou devidamente referenciados, esses poderão ser lidos e avaliados por colegas e professor.

Um dos principais meios de aprendizado do sistema está no contexto de "Atividades", onde os alunos acessam uma variedade de exercícios propostos pelo professor; podendo ser quiz, atividades com tempo, listas em sequência ou atividades passo a passo.

Outro recurso a ser aplicado dentro do contexto de "Atividades" é a árvore de atividades, figura 1. Este recurso fornece uma representação quantitativa e qualitativa da participação do aluno e ao mesmo tempo uma maneira diferente para orientação sequencial dos exercícios.

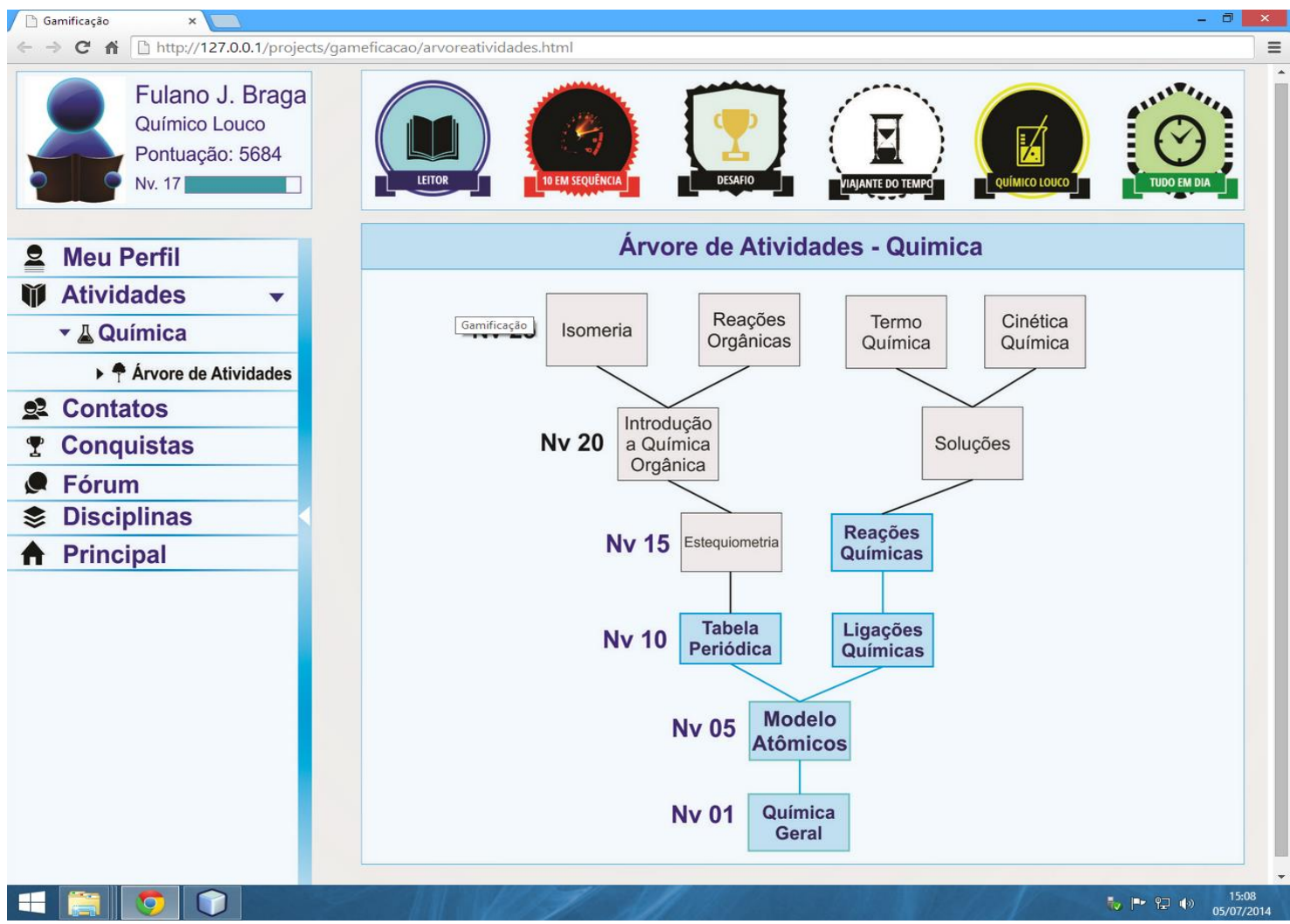

Figura 1 - Interface árvore de atividades genérica para a disciplina de química

A árvore fornece ao professor um meio de ordenar de forma sequencial os conteúdos, considerando o nível de dificuldade e os pré-requisitos necessários para que o aluno consiga realizar estas atividades. Para avançar entre os conteúdos o aluno deve cumprir uma série de requisitos, como fazer todas as atividades dos níveis inferiores atingindo uma taxa de acerto adequada e o mesmo tempo já ter atingido o nível mínimo necessário, desta maneira evita que o aluno que não tenha conhecimento suficiente se frustre ao tentar realizar atividades sem o devido preparo.

A árvore também fornece um esquema prático para a interdisciplinaridade, possibilitando a inserção de pré-requisitos para a liberação dos níveis superiores que envolvam outras disciplinas. Por exemplo, para liberar atividades relacionadas a 
geografia do Brasil, primeiro o aluno deve cumprir as atividades de história relacionadas ao descobrimento do Brasil.

As métricas, níveis e/ou pontuações, são representações quantificadas da participação e comportamento dos alunos (Bista et al, 2012). Tais medidas criam um sentimento de realização nos membros e os motivam a contribuir mais para a comunidade. Uma vez que eles recebem medalhas, emblemas, títulos, passam de nível ou liberam novos conteúdos e atividades, os alunos passam a se envolver mais com o sistema e a contribuir mais para as atividades, aumentando assim o tempo de permanência na ferramenta.

$\mathrm{Na}$ terceira fase, os pontos a serem elencados para ações são identificados e as regras para isto são estabelecidas na quarta fase. Os pontos são conquistados pelos alunos que realizam certas ações dentro de um contexto. As regras definem quantos pontos são alocados para cada ação.

Os conjuntos de conquistas e emblemas são identificados na quinta fase, enquanto que as regras para as conquistas e emblemas são realizadas na fase final. Há dois tipos de emblemas: permanentes e temporários. Os temporários são obtidos através de um determinado comportamento e podem ser perdidos caso tal comportamento não seja recorrente. Já os permanentes são obtidos ao atingir algum avanço no seu tempo de participação ou obtendo alguma conquista especifica.

A figura 2 apresenta alguns emblemas que podem ser utilizados durante a utilização do sistema pelo aluno.
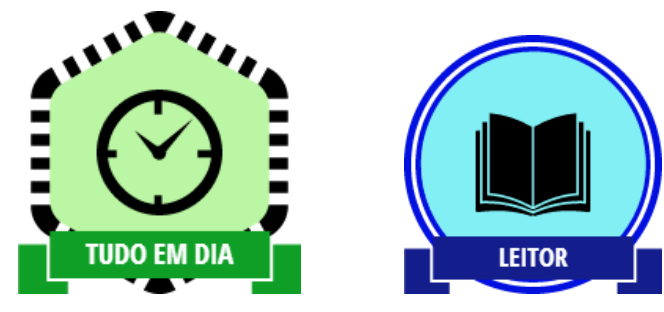

Figura 2 - Modelos de emblemas variados
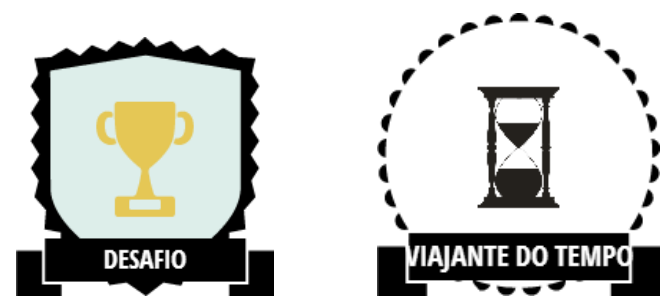

Posteriormente os emblemas serão embutidos em diferentes contextos do usuário, como: leituras, comentários, avaliações, publicações, participações, realizações, entre outros contextos que poderão surgir no desenvolvimento da ferramenta. A pontuação do aluno no geral ou em tarefas específicas também influencia na obtenção de emblemas. Por exemplo, pode-se atribuir um emblema ao aluno após atingir um nível de pontuação ou ao completar com êxito uma série de atividades que estão associadas a um emblema.

\section{Metodologia e desenvolvimento}

Para o desenvolvimento desta ferramenta é necessário aplicar corretamente as ferramentas de análise e desenvolvimento de software, incluindo a correta utilização dos modelos de Interação Humano Computador (IHC).

A ferramenta está sendo desenvolvida na forma de aplicação web, utilizando o modelo de desenvolvimento de ciclo de vida incremental, onde para cada funcionalidade todas as etapas de desenvolvimento são repetidas, sendo incluída uma etapa para a análise da IHC que será realizada com base no modelo de ciclo de vida estrela, que fornece uma maior flexibilidade ao longo do desenvolvimento. 
A interface do sistema, mostrada na figura 3, está sendo modelada com bases nos princípios de Gestalt de proximidade, simetria, continuidade, similaridade, fecho e de destino comum, também será analisada e desenvolvida conforme a responsividade, ou seja, a resposta da interface para mudanças de resolução, tornando o sistema mais acessível ao se utilizar através de um dispositivo móvel.

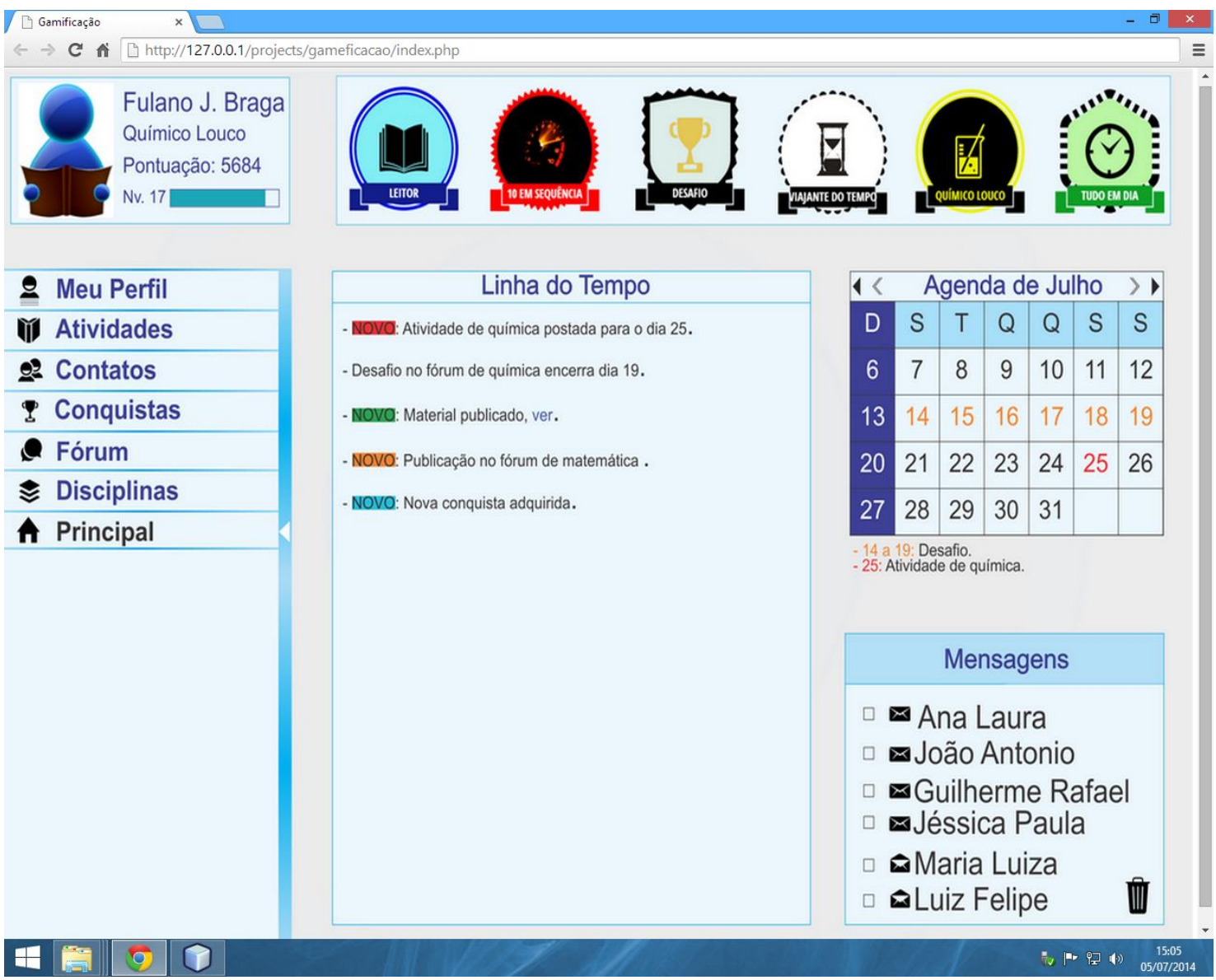

Figura 3 - Interface inicial do sistema

Adicionalmente há o trabalho de programação, o qual requer ajustes a cada etapa do seu desenvolvimento, podendo ser aplicado aos alunos e professores uma versão de testes para obtenção de dados sobre usabilidade e experiência do usuário. A princípio os testes podem ocorrer sobre um grupo (classe) controlado de usuários obtendo resultados através de observações e questionários para avaliação de feedback.

A ferramenta pode ser aplicada a princípio para testes em uma classe específica, sendo acessada somente por um grupo controlado de estudantes de uma matéria. Sendo encaminhado aos alunos e professor alguns questionários para obtenção de feedback sobre a utilização do sistema, sendo assim um protótipo funcional aplicado em um ambiente controlado para testes.

Ela possibilita o levantamento de relatórios sobre as visitas e participação no web site, também podem ser levantados os resultados referentes aos emblemas e pontuação de cada usuário, bem como a influência de tal artefato no resultado final, assim como, podem ser levantados dados sobre a utilização do sistema frente a outras plataformas de auxílio à aprendizagem, como o Moodle. 
Algumas atividades que a ferramenta proporciona podem ser analisadas especificamente, especialmente as realizadas semanalmente ou quinzenalmente, pois estas são explicitamente publicadas pelo professor referente ao conteúdo ministrado em sala de aula. Desta forma, a participação e realização correta destas atividades influenciam no desempenho final do aluno.

Por fim podemos analisar a influência que o sistema atingiu no desempenho geral da turma ao final do período letivo comparando, se possível, com dados de outros períodos.

\section{Resultados esperados}

Existe um grande número de ferramentas de apoio ao ensino, entretanto, na maioria dos casos o uso efetivo do sistema pelo aluno é baixo, sendo assim espera-se estimular a busca pelo conhecimento fora de sala de aula através do uso de gamificação e de design de jogos, causando uma mudança de comportamento nos alunos e mantendo-os mais tempo no sistema, envolvidos com as mecânicas e funcionalidades da ferramenta. Resultando em uma melhora geral no aprendizado e desempenho dos alunos.

\section{Conclusão}

O uso de ferramentas de apoio ao ensino é incrementado a cada ano. Pode-se observar tal fato ao analisar somente as estatísticas do ambiente Moodle. O Brasil encontra-se em $3^{\text {o }}$ lugar entre os países que mais utilizam tal sistema com aproximadamente 4.200 sites registrados, atrás dos Estados Unidos com 10.800 e Espanha com 5.400; possui mais de 49.000 usuários cadastrados somente considerando os 3 maiores sites (Moodle, 2014).

A ampla utilização de ambientes de aprendizagem, a exemplo do Moodle, comprova que tais sistemas de apoio possuem uma grande demanda em instituições de ensino. Tal estatística poderia ser ainda maior caso houvesse incentivo correto para a interação e participação efetiva dos alunos.

Ambientes de aprendizagem fornecem formas de acesso ao conteúdo extraclasse e os estudantes assimilam os conteúdos abordados em sala de aula com maior facilidade quando utilizam tais ambientes. Dessa forma, sistemas de apoio à aprendizagem precisam implantar algumas técnicas que gerem engajamento do estudante com o aprendizado fora de sala de aula.

Técnicas de gamificação visam atingir o engajamento dos estudantes utilizando diferentes formas de motivação, porém, existem poucas pesquisas relacionando gamificação à educação (Simone, et al. 2013). Este artigo propôs uma abordagem criativa para uma ferramenta de apoio ao ensino, onde aplica alguns conceitos de gamificação para aumentar o comprometimento dos alunos fora da sala de aula.

Este cenário justifica a inserção de tal pesquisa dentro da universidade, procurando desenvolver sistemas de apoio ao ensino que favoreçam as motivações intrínseca e extrínseca, assim como a participação efetiva dos alunos; tudo isso visando alcançar os objetivos pedagógicos em uma instituição de ensino. 


\section{Referencias}

Bista, S. K., Nepal, S., Ccolineau, N. e Paris, C. (2012) "Using Gamification In An Online Community", Collaborative Computing: Networking, Applications and Worksharing (CollaborateCom).

Borges, S. S.; Reis, H. L.; Durelli, V. H. S.; Bittencourt, I. I.; Jaques, P. A.; Isotani, S. (2013) "Gamificação Aplicada à Educação: Um Mapeamento Sistemático". Em II Congresso Brasileiro de Informática na Educação, XXIV Simpósio Brasileiro de Informática na Educação.

Daniels, M. (2010) "Businesses Need To Get In The Game". Marketing Week. http://www.marketingweek.co.uk/disciplines/market-research/opinion/businessesneed-to-get-in-the-game/3018554.article.

Deterdings S., Dixon D., Khaled R. e Nacke L. E. (2011) "Gamification: Toward a Definition".

França M. R. e Reategui B. E, (2013) "SMILe-BR: aplicação de conceitos de gamificação em um ambiente de aprendizado baseado em questionamento.” Em II Congresso Brasileiro de Informática na Educação, XXIV Simpósio Brasileiro de Informática na Educação.

Lee, H. e Doh, Y. Y. (2012) "A study on the relationship between educational achievement and emotional engagement in a gameful interface for video lecture systems".

Moodle[Online] (2014). Disponível em: https://moodle.org/ junho.

Moraes C. R. e Varela S. "Motivação do aluno durante o processo de ensinoaprendizagm." - Revista Eletrônica de Educação. Ano I, No. 01.

Prensky M. (2001) "Digital natives, digital immigrants Part 1". On the horizon. Vol 9 Iss:5, PP $1-6$.

Shneiderman B. (2004) "Designing for Fun: How Can We Design User Interfaces to Be More Fun?” Interactions, 11(5), 48-50.

Tapia, J. A.; Fita, E. C. “A motivação em sala de aula: o que é, como se faz”. São Paulo: $7^{\mathrm{a}}$ edição - Edições Loyola, 2006. 316 p.

Viola, F. (2011) "Gamification I Videogiochi Nella Vita Quotidiana", published by Arduino Viola.

Von A. e Dabbish L. (2008) "Designing Games With a Purpose." Communications of the ACM, 58-67. 